\title{
U midade do solo no semiárido pernambucano usando-se reflectometria no domínio do tempo (TDR) ${ }^{1}$
}

\author{
Thais E. M. dos Santos ${ }^{2}$, Abelardo A.A. M ontenegro ${ }^{3} \&$ D emetrius D. Silva $^{4}$
}

\begin{abstract}
RESUMO
O bjetivou-se com o presente trabalho investigar a variabilidade temporal do conteúdo superficial da água no solo, através da reflectometria no domínio do tempo (TDR), em consequência das características de precipitação ocorridas no semiárido pernambucano, estudando esta dinâmica sob diferentes tipos de cobertura superficial do solo. 0 estudo foi realizado em uma encosta de uma bacia representativa, em um Argissolo Amarelo Eutrófico típico, onde foram instaladas quatro parcelas experimentais dotadas de duas sondas TDR, para investigação da umidade do solo e do sistema para monitoramento do escoamento superficial. O s tratamentos adotados foram: cobertura natural (CN), solo descoberto (SD), palma forrageira (P) e barramentos, associados à cobertura morta $(B+C M)$. A partir dos resultados obtidos durante 0 período de ocorrência de chuvas erosivas, a umidade do solo apresentou elevada variabilidade no tempo, estando relacionada aos diferentes tipos de cobertura e propriedades do solo. A cobertura morta mostrou ser a prática conservacionista mais adequada para manutenção da umidade do solo.
\end{abstract}

Palavras-chave: conteúdo de água do solo, precipitação, condições de superfície, variabilidade temporal, REHISA

\section{Soil moisture in Pernambuco semiarid using time domain reflectometry (TDR)}

\begin{abstract}
Present study aimed to investigate the temporal variability of surface water content in soil by time domain reflectometry (TDR), as consequence of precipitation characteristics of Pernambuco semiarid, studying such dynamics under different types of the soil cover. The study was conducted in a slope of a representative catchment, in a Typic Hapludalf soil, where four experimental plots were installed with two TDR probes for soil moisture investigation as well as monitoring the runoff. Treatments were natural cover $(C N)$, bare soil $(S D)$, cactus $(P)$ and microdams associated with mulch $(B+C M)$. From the results obtained during a period with erosive rainfall, it was found that soil moisture observed during the experimental period showed high variability in time, related to different types of coverage and soil properties. Mulching was the most appropriate conservation practice for maintaining soil moisture.
\end{abstract}

Key words: soil water content, precipitation, surface conditions, temporal variability, REHISA

${ }_{1}^{1}$ Parte da Tese de Doutorado do primeiro autor, apresentada ao PPG em Ciência do Solo, UFRPE

2 Instituto de Ciências Ambientais e Desenvolvimento Sustentável/U FBA, Rua Prof. José Seabra s/n, CEP 47805-100, Barreiras, BA. E-mail: thais.emanuelle@ufba.br

${ }^{3}$ D epartamento de Tecnologia Rural/U FRPE, Rua D om M anoel de Medeiros s/n, Dois Irmãos, CEP 52171-900, Recife, PE. Fone: (81) $3320-6273$. E-mail: thaisemanuelle@hotmail.com; abelardo.montenegro@yahoo.com.br

${ }^{4}$ DEA/UFV, Av. PH Rolfs s/n, CEP 36570-000, Viçosa, MG. E-mail: david@ufv.br 


\section{INTRODUÇÃO}

Em condições extremas de seca, a água é o principal fator que influencia as mudanças ambientais. O conteúdo de água do solo limita o número e o tamanho das espécies de plantas perenes em áreas áridas (Pan et al., 2008). A dinâmica da água no solo é, portanto, de grande importância para a vegetação. De acordo com Chen et al. (2007), a dinâmica de água no soloé afetada por uma série de fatores, tais como, topografia, propriedades físicas do solo, cobertura vegetal, precipitação e condições meteorológicas. Na agricultura familiar de sequeiro do semiárido pernambucano o manejo e a conservação do solo são fatores decisivos para viabilizar este tipo de agricultura e possibilitar a recuperação de terras degradadas.

Alguns estudos foram realizados no semiárido (Santos et al., 2009; Santos et al., 2008; Albuquerque et al., 2002), com o objetivo de avaliar o efeito da implementação de práticas conservacionistas no meio ambiente. Albuquerque et al. (2002), estudando perdas de água em parcelas de erosão com $4 \%$ de declive, cultivadas com palma forrageira, verificaram que o cultivo em nível em relação àquele em desnível, reduziu as perdas de água em 20\%. Santos et al. (2009) constataram, em estudos realizados sob chuva simulada, que nos sistemas com adoção da cobertura morta e do cultivo em nível mais barramentos de pedra, a umidade do solo mostrou-se consideravelmente mais elevada em relação à prática do cultivo morro abaixo.

A umidade do solo possui elevado grau de variabilidade no espaço e no tempo, controlada por muitos fatores, tais como tempo, textura do solo, vegetação e topografia. A compreensão do equilíbrio da umidade do solo e da sua variabilidade (espacial e temporal) é fundamental para quantificar a relação entre região, ecologia, hidrologia e geologia (Richard et al., 2004).

A umidade do solo é importante para o crescimento das plantas, estando altamente relacionada com as características temporais e de intensidade dos eventos pluviométricos. A precipitação efetiva depende, assim, da intensidade da chuva, da taxa na qual a água é removida do solo através do escoamento superficial, percolação profunda ou drenagem e a evaporação da superfície do solo (Ampofo, 2006).

Chen et al. (2007) estudaram o efeito de diferentes condições de superfície na umidade do solo e geração de escoamento superficial, em região árida da China e verificaram que, para a conservação da água a vegetação, formada por gramíneas e plantas herbáceas, foi a mais efetiva na conservação da umidade enquanto o cultivo morro abaixo foi menos eficiente na manutenção da umidade do solo.

A reflectometria no domínio do tempo (TDR) tem sido amplamente usada nas últimas décadas (Pereira et al., 2006; Medeiros et al., 2007), visando ao monitoramento da umidade superficial do solo, permitindo descrição detalhada desta variável, ao longo do tempo. As medidas de TDR e do conteúdo de água no solo são baseadas na forte correlação observada entre a constante dielétrica do solo e seu conteúdo volumétrico de água (Greco \& Guida, 2008).

Alguns estudos, nos quais se utiliza este equipamento, têm sido conduzidos no mundo. Cantón et al. (2004) empregaram o equipamento TDR para descrever o comportamento da umidade do solo sob diferentes condições de superfície em região semiárida da Espanha, enquanto Ramos \& MartínezCasasnovas (2006), o utilizaram para estudos da variabilidade espacial do conteúdo de água no solo em um cultivo de uva após o terreno ter sido nivelado, sob clima Mediterrâneo, o qual é caracterizado por baixas temperaturas e precipitações de alta intensidade e curta duração (precipitação média anual de $550 \mathrm{~mm})$.

O objetivo deste trabalho foi investigar a variabilidade temporal do conteúdo superficial da água no solo sob diferentes tipos de cobertura superficial do solo, através da reflectometria no domínio do tempo (TDR), considerando-se as características de precipitação ocorridas no semiárido pernambucano.

\section{Material e MÉTODOS}

\section{Área de estudo}

O estudo foi desenvolvido no Município de Pesqueira, PE, na Bacia Representativa do Alto Ipanema, com área de 183 km², localizada na Região Agreste do Estado de Pernambuco, entre $8^{\circ} 34^{\prime} 17^{\prime \prime}$ e $8^{\circ} 18^{\prime} 11^{\prime \prime}$ de Latitude Sul, e $37^{\circ} 1^{\prime} 35^{\prime \prime}$ e $36^{\circ} 47^{\prime} 20^{\prime \prime}$ de Longitude Oeste. O clima é semiárido muito quente, tipo Estepe, segundo Köeppen; a precipitação média anual é de $607 \mathrm{~mm}$, com temperatura média de $23^{\circ} \mathrm{C}$ e evapotranspiração potencial em torno de $2.000 \mathrm{~mm}$ por ano. A vegetação predominante é a caatinga hipoxerófila (Montenegro \& Montenegro, 2006).

\section{Descrição do experimento}

$\mathrm{O}$ experimento foi conduzido em uma encosta da bacia representativa, com declividade de 5\%; o solo da área foi classificado como Argissolo Amarelo Eutrófico típico, cujas características físicas se encontram na Tabela 1.

\section{Parcelas experimentais}

A determinação das perdas de água foi realizada em campo, em quatro parcelas experimentais instaladas em uma unidade de Argissolo; a parcela foi delimitada por alvenaria, com dimensão de 4,5 m de largura e $11 \mathrm{~m}$ de comprimento sendo instalado, na extremidade inferior, sistema coletor de enxurrada

Tabela 1. Características físicas do solo estudado na área experimental

\begin{tabular}{|c|c|c|c|c|c|c|c|}
\hline $\begin{array}{l}\text { Profundidade } \\
\text { (cm) }\end{array}$ & Horizonte & Areia & $\frac{\text { Argila }}{\left(\mathrm{g} \mathrm{kg}^{-1}\right)}$ & Silte & $\begin{array}{l}\text { ADA } \\
(\%)\end{array}$ & $\begin{array}{c}D p \\
\left(\mathrm{~kg} \mathrm{dm}^{-3}\right)\end{array}$ & $\begin{array}{c}\text { Ds } \\
\left(\mathrm{kg} \mathrm{cm}^{-3}\right)\end{array}$ \\
\hline $\begin{array}{c}0-17 \\
17-92 \\
92-150\end{array}$ & $\begin{array}{l}\text { Ap } \\
\text { Bt1 } \\
\text { Bt2 }\end{array}$ & $\begin{array}{l}342,4 \\
249,1 \\
182,4\end{array}$ & $\begin{array}{l}290,9 \\
404,3 \\
430,9\end{array}$ & $\begin{array}{l}366,7 \\
346,7 \\
386,7\end{array}$ & $\begin{array}{l}13,53 \\
19,20 \\
18,53\end{array}$ & $\begin{array}{l}2,66 \\
2,70 \\
2,72\end{array}$ & $\begin{array}{l}1,73 \\
1,74 \\
1,75\end{array}$ \\
\hline
\end{tabular}

Dp- densidade das partículas; Ds- densidade do solo; ADA- argila dispersa em água 
constituído de uma calha conectada por uma tubulação de PVC, a um primeiro tanque de alvenaria, localizado imediatamente abaixo da parcela; este tanque, por sua vez, estava conectado ao segundo tanque de alvenaria, através de uma tubulação de PVC, na qual o excedente de enxurrada era direcionado ao segundo.

Após cada chuva o volume total de água escoado das parcelas era medido através de metodologia proposta por Cogo (1978).

Em estudos de erosividade da precipitação realizados em anos anteriores para a área de estudo, observou-se ser nos meses de janeiro a maio que ocorrem chuvas de elevado potencial erosivo; neste estudo, a investigação da dinâmica de umidade do solo foi realizada durante os meses de fevereiro a abril de 2010.

Em cada parcela se instalaram duas sondas TDR, distanciadas $1 \mathrm{~m}$, para determinação do conteúdo de umidade do solo, na profundidade de $20 \mathrm{~cm}$; as referidas sondas foram construídas no Laboratório de Solo e Água do Departamento de Tecnologia Rural da UFRPE.

Para calibração das sondas estabeleceram-se 21 pontos de coleta, em duas condições de umidade, seca e úmida; em seguida se correlacionaram as leituras realizadas pelo equipamento e a umidade gravimétrica determinada em laboratório, tendo-se observado ajuste polinomial com coeficiente de determinação de 0,9 .

Um pluviógrafo automático, modelo TB4-L Rain Gauge da Campbell Scientific, com resolução de 0,254 mm, também estava instalado na área para registro da precipitação; a TDR e o pluviógrafo estavam acoplados a um datalogger modelo CR1000, programado para registrar os eventos a cada 5 min; a partir dos dados armazenados, as alturas de precipitação e a intensidade de chuva foram analisadas.

Registros da temperatura, umidade relativa do ar, radiação solar e precipitação, foram obtidos em uma estação meteorológica automática modelo Campbell, instalada na área central da bacia.

Adotaram-se os seguintes tratamentos nas parcelas experimentais: cobertura natural $(\mathrm{CN})$; palma forrageira $(\mathrm{P})$, cultivada no espaçamento de $0,25 \times 0,5 \times 3,0 \mathrm{~m}$, de modo a formar barreiras para contenção do escoamento superficial; barramentos de pedra com aproximadamente $8 \mathrm{~cm}$ de altura com cobertura morta $(\mathrm{B}+\mathrm{CM})$ e solo descoberto (SD). A cobertura morta aplicada foi a palha do capim elefante (Pennisetum purpureum Schum), com densidade de 6,18 Mg ha $^{-1}$.

Visando à determinação da curva de retenção de água, coletaram-se amostras com estrutura preservada em anéis metálicos, em três repetições, nas profundidades de leituras da umidade, através da câmara de pressão de Richards (Richards, 1965), do Laboratório de Física do Solo do Departamento de Engenharia Agrícola da UFV; obtiveram-se as umidades do solo na base de volume, para as tensões matriciais de 10; 33; 100; 500 e $1500 \mathrm{kPa}$; as curvas de retenção foram ajustadas pelo modelo de Genuchten (1980), utilizando-se o "software" Statistica 6.0 (Statsoft, 2001), apresentando coeficientes de determinação de 0,99 para a profundidade de $20 \mathrm{~cm}$. O ponto de murcha teórico foi estimado em $0,071 \mathrm{~cm}^{3} \mathrm{~cm}^{-3}$, enquanto a capacidade de campo foi de $0,15 \mathrm{~cm}^{3} \mathrm{~cm}^{-3}$.
O cálculo de umidade do solo, correspondente a cada tensão matricial na câmara de Richards no intervalo de aproximadamente $24 \mathrm{~h}$, foi efetuado com base no método proposto pela EMBRAPA (1997).

\section{Análise estatística}

Os dados foram submetidos à análise multivariada com medidas repetidas ao longo do tempo e avaliada a retenção de umidade do solo nos diferentes tratamentos, até seis dias após a ocorrência de determinada intensidade de precipitação, culminando em 14 eventos de precipitação, que foram considerados blocos. Realizou-se a análise estatística utilizando-se o pacote estatístico SAS - Statistical Analitical System (SAS, 1998). Para comparação entre as médias dos tratamentos adotou-se o teste de Tukey a nível de significância de $5 \%$ e, na definição de tais eventos (blocos), considerou-se também a umidade antecedente de um dia.

\section{Análise da dependência temporal}

Para a análise da dependência temporal utilizou-se o software $\mathrm{GS}^{+}$(Robertson, 1998). As informações diárias da TDR permitem analisar a dependência temporal da umidade do solo para cada tratamento, a partir da verificação dos parâmetros básicos dos semivariogramas temporais, que podem ser expressos como (Eq. 1):

$$
\gamma(\mathrm{t})=\frac{1}{2 \mathrm{~N}(\mathrm{t})} \sum\left(\mathrm{Z}\left(\mathrm{t}_{\mathrm{i}}\right)-\mathrm{Z}\left(\mathrm{t}_{1}+\mathrm{T}\right)\right)^{2}
$$

em que:

$$
\begin{aligned}
& \gamma(\mathrm{t}) \text { - semivariância temporal para " } \mathrm{t} \text { " } \\
& \mathrm{Z} \text { - propriedade de interesse } \\
& \mathrm{T} \text { - incremento tempo }
\end{aligned}
$$

A partir dos semivariogramas gerados, em particular a partir do patamar e do alcance, é possível avaliar a dependência temporal da variável de interesse, identificando as condições de cobertura que conduzem ao maior grau de dependência temporal da variável. A fim de normalizar os dados, escalonaramse os semivariogramas experimentais calculados. Tais semivariogramas foram ajustados posteriormente a modelos teóricos levando-se em consideração diferentes escalas de variação temporal, incluindo o possível comportamento sazonal e tendências de longa duração, usualmente verificadas na literatura, em análises de variabilidade temporal (Cesare et al., 2002).

\section{Efetividade da água no solo}

Avaliou-se a efetividade da água no solo através da seguinte expressão (Eq. 2), proposta por Porporatto et al. (2002).

$$
\mathrm{SW}_{\mathrm{E}}=\frac{\mathrm{S}_{\mathrm{i}}-\mathrm{S}_{\mathrm{w}}}{\mathrm{S}_{\mathrm{CC}}-\mathrm{S}_{\mathrm{w}}}
$$

em que:

$$
\mathrm{S}_{\mathrm{i}} \text { - umidade atual do solo }
$$


$\mathrm{S}_{\mathrm{CC}}$ - umidade do solo na capacidade de campo

$\mathrm{S}_{\mathrm{w}}$ - umidade do solo no ponto de murcha permanente

A efetividade da umidade do solo pode ser classificada em cinco grupos (Tabela 2), conforme proposto por Chen et al. (2007).

Tabela 2. Critério para avaliação da efetividade da água no solo

\begin{tabular}{cl}
\hline $\mathbf{S W}_{\mathbf{E}}$ & \multicolumn{1}{c}{ Efetividade } \\
$>1,00$ & Extremamente efetivo \\
$0,75-1,00$ & Alta efetividade \\
$0,50-0,75$ & Moderada a alta efetividade \\
$0,25-0,50$ & Baixa efetividade \\
$0,00-0,25$ & Efetividade marginal \\
$<0,00$ & Não efetivo \\
\hline
\end{tabular}

Fonte: Chen et al. (2007)

\section{RESULTADOS E DISCUSSÃO}

Na Figura 1 se encontram a lâmina precipitada, a temperatura do ar e a evapotranspiração para o período de monitoramento. Durante o período de estudo ocorreram 26 eventos de precipitação, que totalizaram $479,30 \mathrm{~mm}$, dentre os quais $42,30 \%$ apresentaram lâmina de precipitação superior a $10 \mathrm{~mm}$, mas apenas cinco eventos possuíam intensidade superior a $10 \mathrm{~mm} \mathrm{~h}^{-1}$; os demais eventos eram de intensidade inferior a $10 \mathrm{~mm} \mathrm{~h}^{-1}$. A maior intensidade de precipitação ocorreu em 14/04, com valor de $67,68 \mathrm{~mm} \mathrm{~h}^{-1}$.

Apresenta-se, na Figura 2, o comportamento temporal da umidade do solo para os meses de fevereiro, março e abril de 2010; para o mês de fevereiro a precipitação total foi de 82,80 $\mathrm{mm}$; observa-se que, no início do mês, a umidade do solo se encontrava abaixo da umidade no ponto de murcha permanente teórico $\left(0,071 \mathrm{~cm}^{3} \mathrm{~cm}^{-3}\right)$; em 14/02, precipitou uma lâmina de $27,6 \mathrm{~mm}$. Apesar de ter sido de baixa intensidade, com valor de $20,8 \mathrm{~mm} \mathrm{~h}^{-1}$ (Tabela 3), gerou-se incremento de umidade do solo para todas as condições de superfície porém este incremento foi menos acentuado para a condição de solo descoberto, que permaneceu com o menor teor de água.

A presença de vegetação ou de impedimentos ao livre escoamento nos demais tratamentos influenciou na contenção do escoamento superficial e proporcionou o incremento de umidade. Tal incremento foi resultado da redução da velocidade do escoamento causada pela presença de resíduos vegetais na superfície o que, geralmente, produz aumento da rugosidade hidráulica do fluxo superficial, com consequente aumento da altura do escoamento (Braida \& Cassol, 1999). Santos et al. (2009) encontraram reduções significativas nas perdas de água para os tratamentos com cobertura morta e barramento em pedra, na região semiárida de Pernambuco.

Observando-se os valores de escoamento superficial ocorridos nas parcelas experimentais (Tabela 3) verifica-se, para o evento ocorrido no dia 14/02, que apenas a parcela descoberta apresentou escoamento superficial constatando-se, então, que praticamente $70 \%$ da chuva que caiu na parcela geraram escoamento superficial decorrente, provavelmente, de selamento superficial justificando, assim, o menor teor de umidade nesta parcela. Galindo et al. (2008), caracterizando os solos e a vegetação em áreas de caatinga apresentando diferentes níveis de degradação, identificaram que atributos do solo refletiram melhor o nível de degradação da vegetação e notaram que a presença de micas parcialmente alteradas (biotita e muscovita), nas frações areias grossa e fina dos horizontes superficiais, pode contribuir para o aumento da susceptibilidade à erosão e encrostamento.

Verifica-se, na Tabela 3, que as perdas totais de água foram 0,$88 ; 147,79 ; 0,44$ e $0,00 \mathrm{~mm}$, para os tratamentos cobertura natural, solo descoberto, barramento associado à cobertura morta e palma forrageira, respectivamente.

Essas diferenças entre os tratamentos estão relacionadas aos níveis de cobertura do solo, já que o tratamento solo descoberto não oferece impedimento ao livre escoamento, o que tende a provocar aumento na velocidade de escoamento superficial, reduzindo então sua infiltração e acarretando, assim, aumento nas perdas totais de água, em detrimento dos demais tratamentos. Verifica-se, ainda, o resultado eficiente obtido no tratamento utilizando-se palma forrageira como barramento ao escoamento, uma vez que não apresentou escoamento superficial durante o período de observação.

Ressalta-se que a umidade antecedente ao evento ocorrido em 14/02, estava próxima ao valor residual (Figura 2A); verificase expressivo umedecimento do solo em consequência da precipitação e de aportes hídricos das camadas mais superficiais.

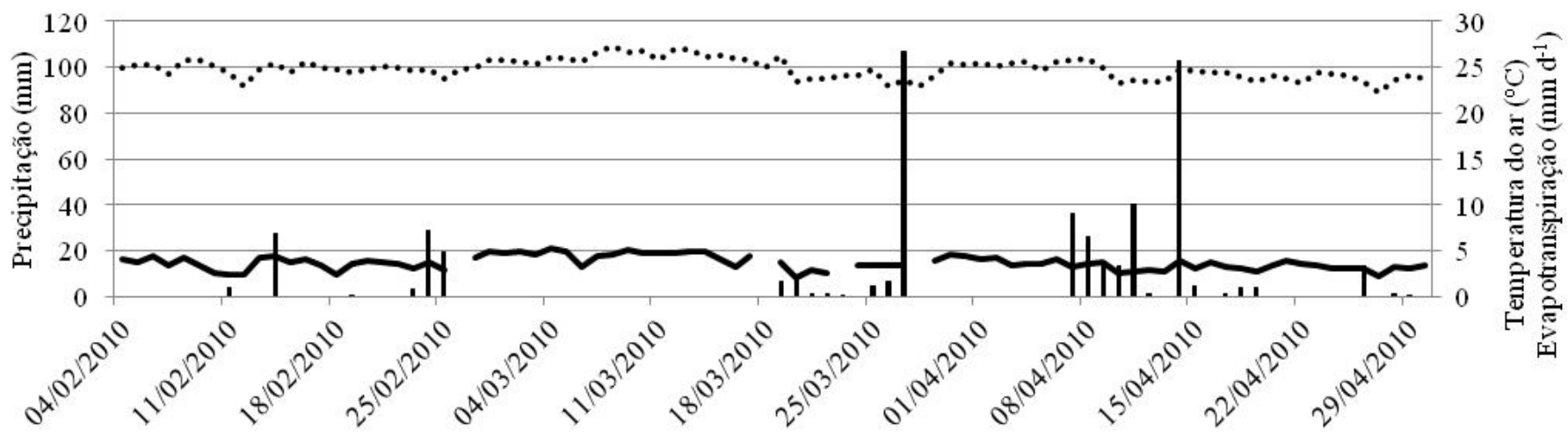

PPT $(\mathrm{mm})$

ET0 $\quad \cdots . . . \cdot$ Temperatura

Figura 1. D istribuição da lâmina precipitada, temperatura e evapotranspiração potencial ocorrida durante o período de estudo, na área experimental 
A.

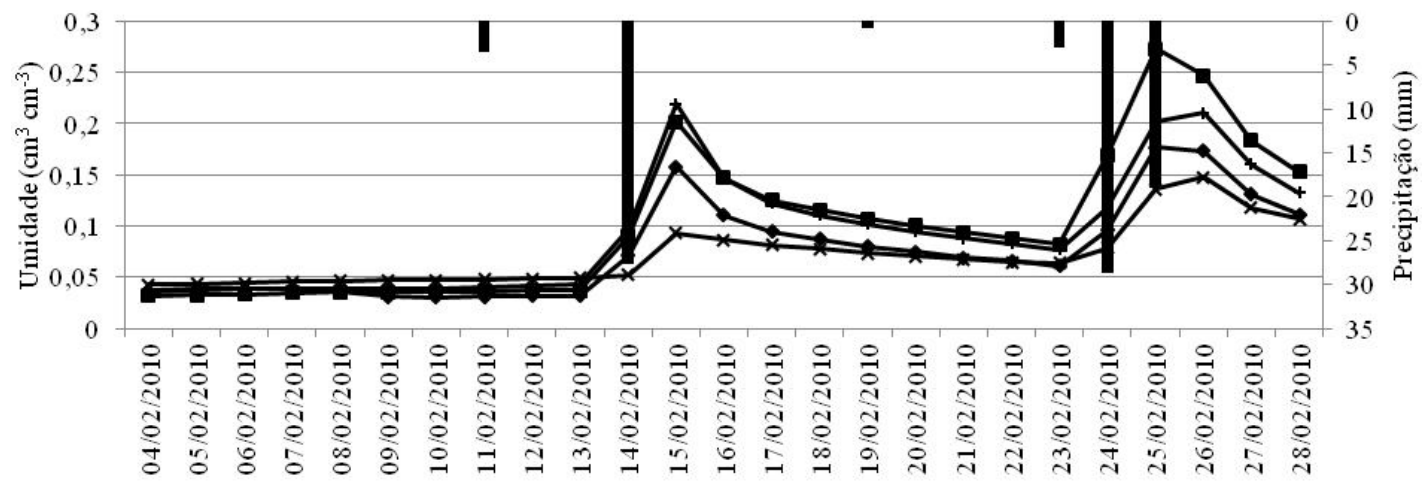

B.

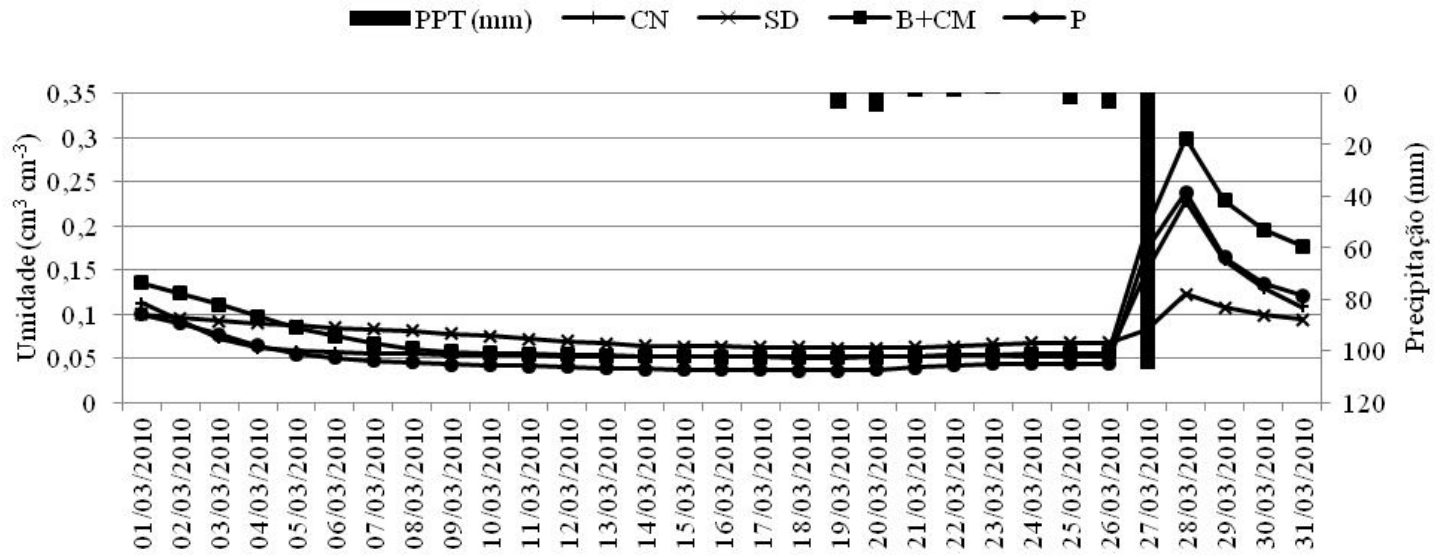

C.
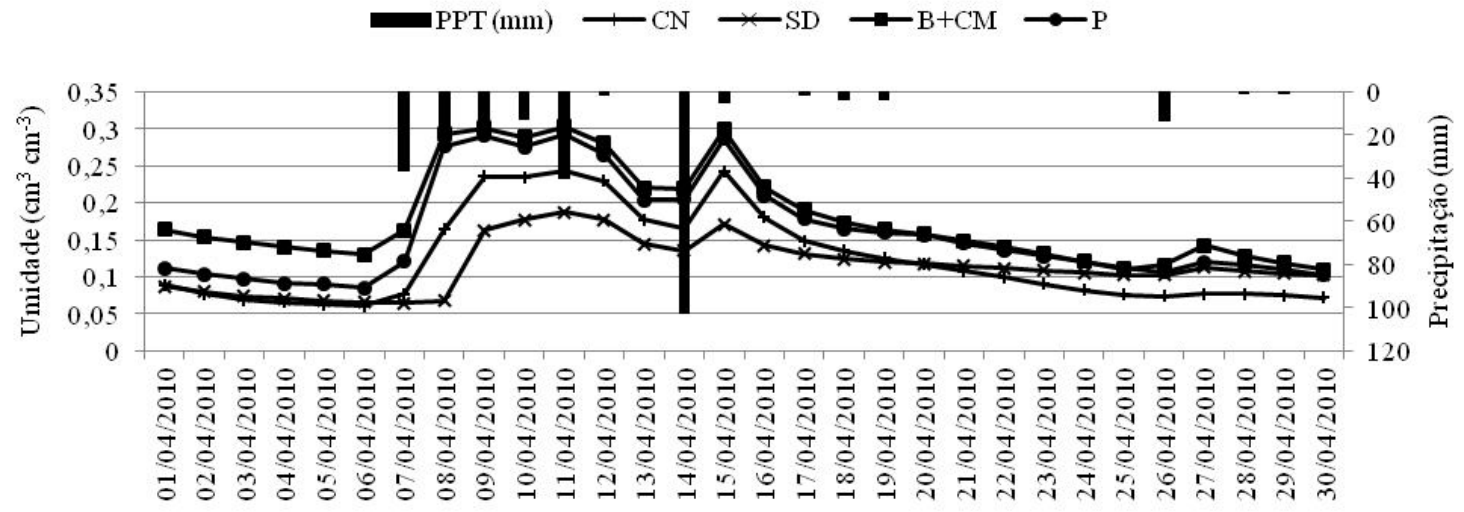

Figura 2. Distribuição da umidade no Argissolo Amarelo Eutrófico típico, para os meses de fevereiro (A), março (B) e abril (C) de 2010, em resposta aos eventos de precipitação (PPT) sob diferentes condições de superfície: CN - cobertura natural; SD - solo descoberto; B+ CM - barramentos associados à cobertura morta; P- pal ma forrageira

Com a não ocorrência de precipitação durante os nove dias subsequentes, o solo foi perdendo umidade; as perdas de umidade foram de 63,$33 ; 28,88 ; 59,00$ e 59,33\% para as condições de cobertura nativa, solo descoberto, barramento em pedra e palma forrageira, respectivamente; observa-se que a maior redução encontrada foi para o solo sob cobertura nativa, evidenciando o efeito da evapotranspiração real, uma vez que esta condição de superfície do solo é a que possui maior densidade de cobertura vegetal.

Em 24/02 precipitou uma lâmina de $28,7 \mathrm{~mm}$, praticamente a mesma lâmina precipitada em 14/02 porém a umidade do solo atingiu valores superiores aos valores da umidade na capacidade de campo $\left(0,15 \mathrm{~cm}^{3} \mathrm{~cm}^{-3}\right)$, uma vez que o solo já se encontrava com umidade antecedente superior à do primeiro evento. Pan et al. (2008) estudaram a variabilidade espacial do conteúdo de água no solo, no deserto da China, e verificaram que, em geral, o conteúdo de água no solo, dentre outros fatores, depende do teor de umidade antecedente. Se o solo estiver previamente mais úmido, ele atingirá maiores médias de umidade do solo, embora para uma mesma lâmina de chuva.

Após o evento ocorrido em 25/02, decorreram 6, 12, 9 e 6 dias para que o solo atingisse o ponto de murcha permanente $\left(0,071 \mathrm{~cm}^{3} \mathrm{~cm}^{-3}\right)$, para as condições de cobertura natural, solo descoberto, barramento com cobertura morta e palma forrageira, 
Tabela 3. D ados de precipitação e lâmina escoada nas parcelas experimentais durante o período avaliado

\begin{tabular}{|c|c|c|c|c|c|}
\hline Data & Tratamento $^{*}$ & Precipitação (mm) & Intensidade $\left(\mathrm{mm} \mathrm{h}^{-1}\right)$ & Lâmina escoada (mm) & Perda de água (\% da chuva) \\
\hline $14 / 02 / 10$ & $\begin{array}{c}C N \\
S D \\
B+C M \\
P\end{array}$ & $\begin{array}{l}27,69 \\
27,69 \\
27,69 \\
27,69\end{array}$ & $\begin{array}{l}20,81 \\
20,81 \\
20,81 \\
20,81\end{array}$ & $\begin{array}{r}0,0 \\
18,9 \\
0,0 \\
0,0\end{array}$ & $\begin{array}{r}0,0 \\
68,3 \\
0,0 \\
0,0\end{array}$ \\
\hline $25 / 02 / 10$ & $\begin{array}{c}C N \\
S D \\
B+C M \\
P\end{array}$ & $\begin{array}{l}28,70 \\
28,70 \\
28,70 \\
28,70\end{array}$ & $\begin{array}{l}5,27 \\
5,27 \\
5,27 \\
5,27\end{array}$ & $\begin{array}{l}0,0 \\
7,1 \\
0,0 \\
0,0\end{array}$ & $\begin{array}{r}0,0 \\
24,9 \\
0,0 \\
0,0\end{array}$ \\
\hline $25 / 02 / 10$ & $\begin{array}{c}C N \\
S D \\
B+C M \\
P\end{array}$ & $\begin{array}{l}19,05 \\
19,05 \\
19,05 \\
19,05\end{array}$ & $\begin{array}{l}7,07 \\
7,07 \\
7,07 \\
7,07\end{array}$ & $\begin{array}{l}0,0 \\
8,6 \\
0,0 \\
0,0\end{array}$ & $\begin{array}{r}0,0 \\
45,4 \\
0,0 \\
0,0\end{array}$ \\
\hline $20 / 03 / 10$ & $\begin{array}{c}C N \\
S D \\
B+C M \\
P \\
\end{array}$ & $\begin{array}{l}13,60 \\
13,60 \\
13,60 \\
13,60 \\
\end{array}$ & $\begin{array}{l}10,66 \\
10,66 \\
10,66 \\
10,66 \\
\end{array}$ & $\begin{array}{l}0,0 \\
0,2 \\
0,0 \\
0,0 \\
\end{array}$ & $\begin{array}{l}0,0 \\
1,7 \\
0,0 \\
0,0 \\
\end{array}$ \\
\hline $27 / 03 / 10$ & $\begin{array}{c}C N \\
S D \\
B+C M \\
P\end{array}$ & $\begin{array}{l}106,94 \\
106,94 \\
106,94 \\
106,94\end{array}$ & $\begin{array}{l}52,83 \\
52,83 \\
52,83 \\
52,83\end{array}$ & $\begin{array}{r}0,3 \\
32,8 \\
0,1 \\
0,0\end{array}$ & $\begin{array}{r}0,2 \\
30,6 \\
0,1 \\
0,0\end{array}$ \\
\hline $07 / 04 / 10$ & $\begin{array}{c}C N \\
S D \\
B+C M \\
P \\
P\end{array}$ & $\begin{array}{l}36,32 \\
36,32 \\
36,32 \\
36,32 \\
\end{array}$ & $\begin{array}{l}33,53 \\
33,53 \\
33,53 \\
33,53 \\
\end{array}$ & $\begin{array}{r}0,1 \\
19,6 \\
0,0 \\
0,0 \\
\end{array}$ & $\begin{array}{r}0,2 \\
53,9 \\
0,1 \\
0,0 \\
\end{array}$ \\
\hline $08 / 04 / 10$ & $\begin{array}{c}C N \\
S D \\
B+C M \\
P\end{array}$ & $\begin{array}{l}26,16 \\
26,16 \\
26,16 \\
26,16\end{array}$ & $\begin{array}{l}5,23 \\
5,23 \\
5,23 \\
5,23\end{array}$ & $\begin{array}{l}0,0 \\
7,1 \\
0,1 \\
0,0\end{array}$ & $\begin{array}{r}0,0 \\
27,3 \\
0,5 \\
0,0\end{array}$ \\
\hline $11 / 04 / 10$ & $\begin{array}{c}C N \\
S D \\
B+C M \\
P\end{array}$ & $\begin{array}{l}39,88 \\
39,88 \\
39,88 \\
39,88\end{array}$ & $\begin{array}{l}2,03 \\
2,03 \\
2,03 \\
2,03 \\
\end{array}$ & $\begin{array}{r}0,1 \\
20,4 \\
0,0 \\
0,0 \\
\end{array}$ & $\begin{array}{r}0,1 \\
51,3 \\
0,0 \\
0,0 \\
\end{array}$ \\
\hline $14 / 04 / 10$ & $\begin{array}{c}C N \\
S D \\
B+C M \\
P\end{array}$ & $\begin{array}{l}102,62 \\
102,62 \\
102,62 \\
102,62\end{array}$ & $\begin{array}{l}67,68 \\
67,68 \\
67,68 \\
67,68\end{array}$ & $\begin{array}{r}0,5 \\
32,9 \\
0,1 \\
0,0\end{array}$ & $\begin{array}{r}0,5 \\
32,1 \\
0,1 \\
0,0\end{array}$ \\
\hline
\end{tabular}

* CN- cobertura natural; SD- solo descoberto; $\mathrm{B}+\mathrm{CM}$ - barramentos associados à cobertura morta; P- palma forrageira

respectivamente. Devido à ausência de vegetação, o solo descoberto levou mais tempo para atingir o ponto de murcha permanente; resultados semelhantes foram encontrados por Ampofo (2006), ao observar, durante a estação chuvosa, que a parcela com cobertura morta reteve maior umidade quando comparada com parcelas florestadas e solo descoberto; no entanto, a parcela com cobertura morta perdeu mais umidade para a atmosfera, durante a estação seca.

O comportamento da umidade no mês de março está apresentado na Figura 2B; verifica-se que, passados 32 dias sem ocorrer precipitação, o solo voltou às condições de umidade abaixo do ponto de murcha permanente teórico $(0,071$ $\mathrm{cm}^{3} \mathrm{~cm}^{-3}$ ); em 27/03 a lâmina precipitada foi de $106,9 \mathrm{~mm}$, com intensidade de 52,8 $\mathrm{mm} \mathrm{h}^{-1}$. Segundo Pan et al. (2008), chuvas de alta intensidade podem causar escoamento superficial e, assim, produzir menor incremento de umidade do solo do que chuvas com baixas intensidades. Observando os valores de escoamento superficial ocorridos neste dia nas parcelas experimentais (Tabela 3), verificou-se que nos tratamentos cobertura natural, solo descoberto e barramentos, as respectivas perdas de água em percentagens de chuva caída na parcela experimental, foram 0,$24 ; 30,62$ e $0,12 \%$, valores que explicam o menor incremento de umidade para o solo descoberto, observado na Figura 2B.

Nas Figuras 2B e 2C, observa-se que de 28/03 a 06/04, não houve precipitação e as umidades nos tratamentos que receberam práticas conservacionistas, mantiveram valores mais elevados. Destaca-se o tratamento barramento associado à cobertura morta, que manteve os valores de umidade próximos à capacidade de campo $\left(0,15 \mathrm{~cm}^{3} \mathrm{~cm}^{-3}\right)$. Os quatro dias subsequentes foram de ocorrência de chuvas e o solo atingiu valores próximos à umidade de saturação $\left(0,35 \mathrm{~cm}^{3} \mathrm{~cm}^{-3}\right)$ nos tratamentos barramento e palma, os quais já se encontravam com umidade antecedente elevada; dos dias 11/04 ao 14/04, as perdas de umidade para os tratamentos foram de 33,3; 27,7; 30,0 e $31,0 \%$ para cobertura natural, solo descoberto, barramentos e palma forrageira, respectivamente; novamente se deve salientar a relevância da evapotranspiração na demanda hídrica da parcela com cobertura natural.

Em 14/04 precipitou uma lâmina de 102,6 mm, associada a uma elevada intensidade de $67,7 \mathrm{~mm} \mathrm{~h}^{-1}$, que gerou escoamento nos tratamentos cobertura natural, solo descoberto e 
barramento com cobertura morta. As respectivas perdas de água em percentagens de chuva caída na parcela experimental foram de 0,$47 ; 32,09$ e 0,13\%, respectivamente. Ramos \& MartínezCasasnovas (2006), estudando o efeito das intensidades de chuva no escoamento superficial e umidade do solo, verificaram que as chuvas de alta intensidade apresentaram valores significativamente superiores de escoamento superficial, em detrimento das chuvas de baixa intensidade.

A partir da análise estatística dos dados do conteúdo de água no solo, verificou-se interação entre dias decorridos após o evento de precipitação e a umidade, bem como interação significativa entre tempo e condições de superfície; ambas as interações foram significativas a nível de $1 \%$.

$\mathrm{Na}$ Tabela 4 se encontram as médias dos valores da umidade do solo até seis dias após a ocorrência da precipitação. Observa-se que, antes do dia da ocorrência da precipitação, só havia diferença significativa para as condições de solo sob barramento associado à cobertura morta e à condição de solo descoberto. A cobertura do solo proporcionada pelos resíduos culturais deixados na superfície, tem ação direta e efetiva na redução da erosão hídrica, em virtude da dissipação de energia cinética das gotas da chuva, a qual diminui a desagregação das partículas de solo, o selamento superficial e aumenta a infiltração de água (Cogo et al., 2003). A eficiência da implementação da cobertura morta pode ser observada verificando-se que este tratamento apresentou valores médios de umidade significativamente superiores aos dos demais tratamentos, comprovando ser uma alternativa adequada para a agricultura de sequeiro, visto que mantém a umidade do solo elevada, mesmo após decorridos seis dias da precipitação.

Em relação à utilização da palma forrageira como obstáculo ao escoamento superficial, esta prática também mantém o solo com umidade elevada, igualando-se ao solo com cobertura morta apenas no primeiro dia; ao longo dos seis dias após a precipitação, a umidade do solo não se diferencia estatisticamente da umidade do solo sob cobertura natural. Até o quarto dia e após a ocorrência da precipitação, este tratamento se mantém com teores de umidade média do solo elevados não se diferenciando estatisticamente do solo sob o plantio de palma forrageira; entretanto, com o passar dos dias a média deste tratamento decaiu, não se diferenciando estatisticamente da condição de solo descoberto.

Ressalta-se que a umidade do solo na condição sob cobertura natural aumenta até o segundo dia após a precipitação e, a partir daí, começa a decair. O aumento da média de umidade nos primeiros dias pode ser devido à interceptação vegetal que, após reter parte da precipitação, começa a liberar água para o solo; por outro lado, o fato da umidade do solo, sob esta condição, decair após o terceiro dia (igualando-se à média do solo descoberto) pode ser em virtude da evapotranspiração mais acentuada na primeira condição. Pan et al. (2008), estudando a variabilidade espacial do conteúdo de umidade da superfície do solo em uma região árida da China, verificaram que a vegetação influenciou na variabilidade da umidade do solo, pelo padrão de precipitação imposto pelo dossel, representado pela interceptação vegetal.

A Figura 3 representa o comportamento da umidade do solo nos diferentes tratamentos sob diferentes intensidades de precipitação natural, em ordem cronológica. As chuvas dos perfis de 1 a 4, cujas intensidades são 20,8, 6,1, 5,2 e 7,0 $\mathrm{mm} \mathrm{h}^{-1}$, respectivamente, são efetivas na elevação da umidade do solo em todos os tratamentos. Apesar das chuvas dos perfis de 2 a 4 serem de baixa intensidade, elas conseguem elevar a umidade do solo, o que pode ser explicado pelo fato da primeira chuva ocorrida ser de intensidade mais elevada fazendo com que a umidade do solo alcance níveis superiores à capacidade de campo $\left(0,15 \mathrm{~cm}^{3} \mathrm{~cm}^{-3}\right)$. Em consequência, as precipitações ocorridas posteriormente mantiveram a umidade do solo elevada. Ramos \& Martínez-Casasnovas (2006), estudando o efeito das precipitações na umidade do solo e a geração de escoamento superficial em clima Mediterrâneo, verificaram que as chuvas de alta intensidade aumentaram apenas a umidade da camada superficial do solo e nenhum aumento significativo foi observado para camadas mais profundas; entretanto, sob baixas intensidades de chuva, o incremento de umidade do solo ocorre também em profundidade.

Comprova-se este fato observando-se os perfis 5 e 6 , cujas intensidades de precipitação são iguais a 2,8 e 10,6 $\mathrm{mm} \mathrm{h}^{-1}$, respectivamente. Apesar do perfil 6 representar chuva de intensidade superior às dos perfis 2,3 e 4, esta não eleva a umidade do solo já que o mesmo se encontra com condições de umidade antecedente abaixo da umidade do ponto de murcha permanente $\left(0,071 \mathrm{~cm}^{3} \mathrm{~cm}^{-3}\right)$ e a umidade do solo descoberto se torna superior à das demais condições de cobertura superficial. Resultados semelhantes foram encontrados por Cantón et al. (2004), que avaliaram a umidade do solo sob diferentes condições de superfície, verificando que ela permanece, usualmente, mais elevada sob a vegetação arbustiva do que em áreas descobertas, na profundidade de $15 \mathrm{~cm}$, exceto para precipitações de baixa magnitude, que induzem a um aumento na umidade de solos descobertos, superior ao solo sob vegetação, em razão da interceptação vegetal da chuva.

Este mesmo comportamento é observado para os perfis 7 e 8, que apresentam intensidade de precipitação igual a 4,32 e $10,45 \mathrm{~mm} \mathrm{~h}^{-1}$, não havendo variações na umidade do solo para essas intensidades.

Tabela 4. Médias das umidades no Argissolo Amarelo Eutrófico típico para as diferentes condições de superfície e umidade antecedente, avaliadas em dias subsequentes à ocorrência da precipitação

\begin{tabular}{cllllllll}
\hline Tratamento $^{*}$ & ANC & DC & 1 DAC & 2 DAC & 3 DAC & 4 DAC & 5 DAC & 6 DAC \\
B+CM & $0,125 \mathrm{a}^{(1)}$ & $0,163 \mathrm{a}$ & $0,216 \mathrm{a}$ & $0,219 \mathrm{a}$ & $0,201 \mathrm{a}$ & $0,178 \mathrm{a}$ & $0,167 \mathrm{a}$ & $0,156 \mathrm{a}$ \\
$\mathrm{P}$ & $0,102 \mathrm{ab}$ & $0,136 \mathrm{ab}$ & $0,182 \mathrm{ab}$ & $0,184 \mathrm{~b}$ & $0,167 \mathrm{~b}$ & $0,147 \mathrm{~b}$ & $0,139 \mathrm{~b}$ & $0,130 \mathrm{~b}$ \\
$\mathrm{CN}$ & $0,092 \mathrm{ab}$ & $0,123 \mathrm{bc}$ & $0,171 \mathrm{~b}$ & $0,177 \mathrm{~b}$ & $0,162 \mathrm{~b}$ & $0,141 \mathrm{~b}$ & $0,129 \mathrm{bc}$ & $0,116 \mathrm{bc}$ \\
$\mathrm{SD}$ & $0,077 \mathrm{~b}$ & $0,091 \mathrm{c}$ & $0,115 \mathrm{c}$ & $0,126 \mathrm{c}$ & $0,123 \mathrm{c}$ & $0,114 \mathrm{c}$ & $0,109 \mathrm{c}$ & $0,105 \mathrm{c}$ \\
\hline
\end{tabular}

\footnotetext{
(1) Médias seguidas de letras minúsculas na mesma coluna, não diferem entre si, a nível de $5 \%$ de significância, pelo teste de Tukey

* B+ CM- barramento associado a cobertura morta; P- palma forrageira; CN- cobertura natural e SD- solo descoberto. ANC- dia antes da chuva; DC- dia de ocorrência da chuva; DAC- dias após a
} ocorrência da chuva 


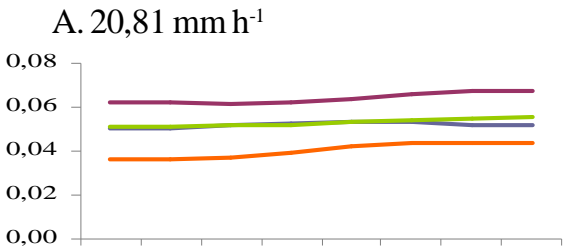

C. $5,27 \mathrm{~mm} \mathrm{~h}^{-1}$
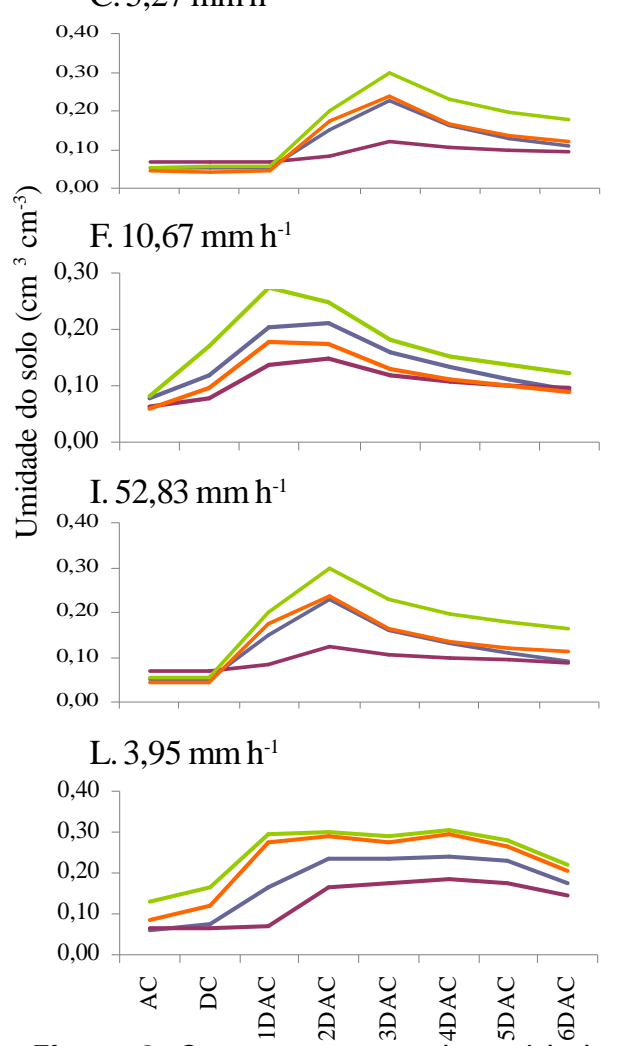

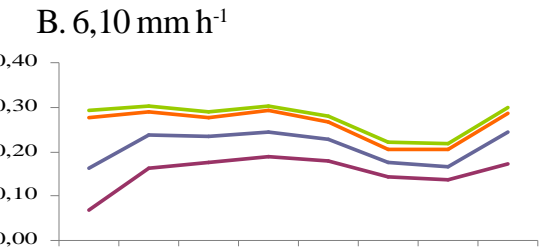

\section{D. $77,07 \mathrm{~mm} \mathrm{~h}^{-1}$}
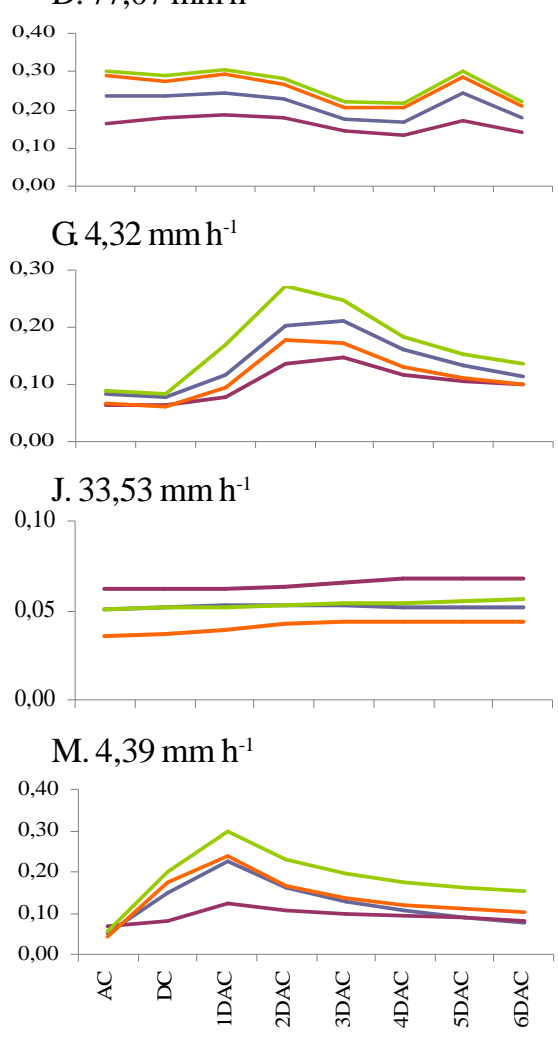
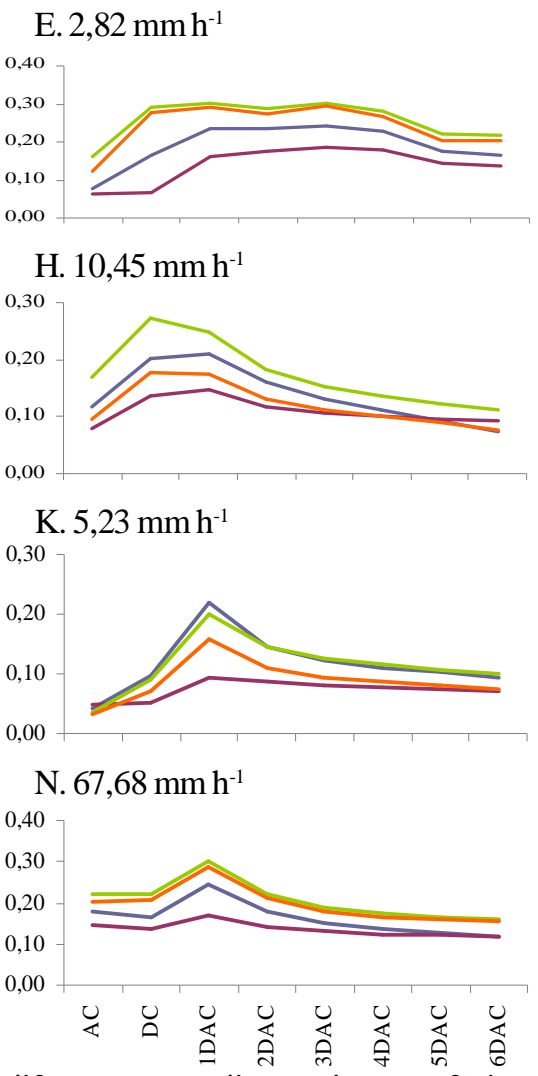

Figura 3. Comportamento da umidade no Argissolo Amarelo Eutrófico típico sob diferentes condições de superfície avaliadas para as intensidades de precipitação ocorridas durante o período experimental. AN C - dia antes da chuva; DC - dia de ocorrência da chuva; D AC - dias após a ocorrência da chuva. CN - cobertura natural; D - solo descoberto; $\mathrm{B}+\mathrm{CM}$ - barramento associado à cobertura morta; $\mathrm{P}$ - palma forrageira

As intensidades de precipitação elevadas, representadas pelos perfis 9 e 10 , de 52,8 e $33,5 \mathrm{~mm} \mathrm{~h}^{-1}$, respectivamente, são efetivas e elevam a umidade do solo em todos os tratamentos. As precipitações ocorridas em seguida, representadas pelos perfis 11,12 e 13, com respectivas intensidades 5,2, 3,9 e 4,3 $\mathrm{mm} \mathrm{h}^{-1}$, apesar de serem de baixa intensidade foram efetivas na elevação e manutenção da umidade do solo, uma vez que a umidade antecedente se encontrava próxima ou superior à umidade na capacidade de campo.

O perfil 14 representa a maior intensidade de precipitação ocorrida neste período, $67,6 \mathrm{~mm} \mathrm{~h}^{-1}$, observando-se um rápido incremento de umidade do solo até um dia após a ocorrência da chuva; em seguida, o solo entra novamente em processo de secamento.

$\mathrm{Na}$ Figura 4 são apresentadas as distribuições de frequências acumuladas dos valores da porcentagem de umidade do solo. Observa-se que os tratamentos palma e barramento associado com cobertura morta apresentam as maiores permanências de valores elevados de umidade do solo, seguidos da cobertura natural e solo descoberto. Adicionalmente, os maiores valores de umidade durante o

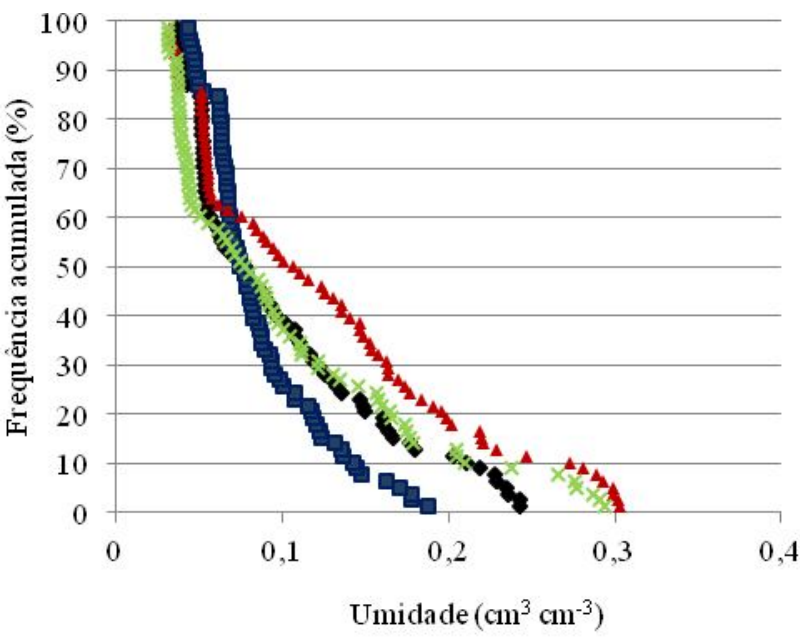

- CN $\square \mathrm{D} \wedge \mathrm{B}+\mathrm{CM} \times \mathrm{P}$

$\mathrm{B}+\mathrm{CM}$ - barramento associado à cobertura morta; $\mathrm{P}$ - palma forrageira; $\mathrm{CN}$ - cobertura natural e SD - solo des coberto

Figura 4. Frequência acumulada para os dados de umidade do Argissolo Amarelo Eutrófico típico durante todo o período experimental 
período experimental, são também observados nos tratamentos palma e barramento associado à cobertura morta.

Observa-se, na Tabela 5, que durante o período experimental mais de $45 \%$ das umidades do solo se apresentaram não efetivos para as condições de solo sob cobertura natural, palma e solo descoberto. Este parâmetro apresentou-se elevado para a condição de solo sob barramento associado à cobertura morta, em que mais de 48,03\% dos valores de umidade apresentaram critério de efetividade de extrema a moderada.

Tabela 5. Efetividade relativa da água no solo sob diferentes condições de superfície

\begin{tabular}{crrccrc}
\hline Tratamentos & $>\mathbf{1}$ & $\mathbf{0 , 7 5 - 1}$ & $\mathbf{0 , 5 - 0 , 7 5}$ & $\mathbf{0 , 2 5 - 0 , 5}$ & $\mathbf{0 - 0 , 2 5}$ & $<\mathbf{0}$ \\
CN & 19,48 & 5,19 & 7,79 & 10,38 & 9,09 & 48,05 \\
P & 6,49 & 6,49 & 9,09 & 10,38 & 22,07 & 45,45 \\
B+CM & 32,46 & 10,38 & 5,19 & 6,49 & 6,49 & 38,96 \\
SD & 24,67 & 2,59 & 3,89 & 10,38 & 10,38 & 48,05 \\
\hline CN- cobertura natural; P-Palma; B CM- barramento associado à cobertura morta; SD- solo
\end{tabular}
descoberto

De modo geral, o mês de março foi o que apresentou a menor efetividade de água no solo devido ao fato deste período ser também o de menor total precipitado.

\section{Análise da dependência temporal}

As condições de cobertura do solo foram analisadas quanto à dependência temporal; na Figura 5, verificam-se os semivariogramas temporais escalonados para as condições de solo descoberto, solo com cobertura morta associada com barramentos, com cobertura natural e solo com palma forrageira, e que os alcances dos semivariogramas temporais dependem da condição de cobertura, em particular para a primeira fase do comportamento periódico. Observa-se, ainda, que o comportamento periódico apresenta período semelhante para todos os tratamentos, conforme evidenciado na Figura 5A, sendo este um indicativo da interferência de fatores externos, como o clima, na distribuição de umidade, atuando de modo similar em todas as parcelas consideradas.

Para a condição de cobertura natural, as semivariâncias temporais aumentam, atingindo patamar próximo a 1,0 para distâncias temporais menores; os tratamentos de cobertura morta e de palma são os que apresentam maiores alcances, resultado este associado a covariâncias temporais mais elevadas. Este resultado é um indicativo da alta dependência temporal dos dados de umidade sob essas condições de superfície, ou seja, realça o potencial da cobertura (consorciada com o barramento) na manutenção da umidade do solo, ao controlar os aportes da chuva e, ao mesmo tempo, reduzir as taxas de perda de umidade por evapotranspiração.

Ainda na Figura 5 se observa ajuste de semivariograma teórico exponencial, com coeficiente de determinação de ajuste de $0,96,0,97,0,97$ e 0,97, para as condições de cobertura natural (CN), solo descoberto (SD), cobertura morta associada a barramento com pedra (CM) e palma forrageira $(\mathrm{P})$.

Os modelos teóricos ajustados podem ser representados na Eq. 3:

$$
\gamma(\mathrm{t})=\mathrm{c}_{0}+\mathrm{c}_{1}\left[1-\exp \left(-\frac{\mathrm{t}}{\mathrm{a}}\right)\right]+\mathrm{c}_{3}\left[1+\cos \left(\frac{2 \pi \mathrm{t}}{\mathrm{c}_{4}}-\pi\right)\right]+\mathrm{c}_{5} \mathrm{t}
$$
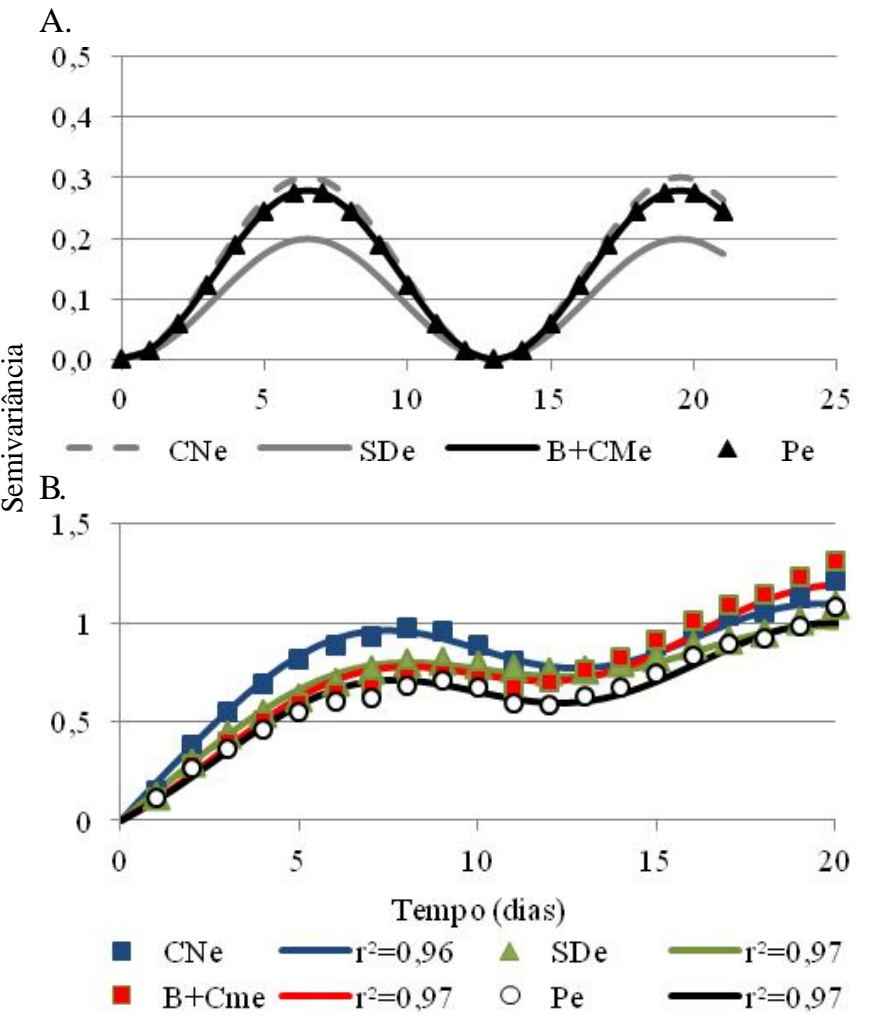

$\mathrm{B}+\mathrm{CMe}$ - barramento associado a cobertura morta; $\mathrm{Pe}$ - palma forrageira; $\mathrm{CNe}$ - cobertura natural e SDe - solo descoberto

Figura 5. Modelos periódicos para as semivariâncias (A); Semivariogramas temporais escalonados e ajustes de modelos teóricos da umidade no Argissolo Amarelo Eutrófico típico na área experimental, em função do tipo de cobertura da superfície (B)

em que, um comportamento exponencial predomina para escala temporal curta e uma tendência de longa duração pode estar presente (observada apenas nos dois tratamentos conservacionistas), sobrepostos a um comportamento periódico de mesmo período, para todos os tratamentos. A Tabela 6 apresenta os parâmetros ajustados para cada tratamento.

Tabela 6. Parâmetros do modelo de semivariograma temporal teórico para os tratamentos

\begin{tabular}{ccccccc}
\hline \multirow{2}{*}{ Trat. $^{*}$} & \multicolumn{7}{c}{ Parâmetros } \\
\cline { 2 - 7 } & c0 & c1 & a & c3 & c4 & c5 \\
CN & 0 & 0,80 & 4,0 & 0,15 & 13 & 0,0 \\
SD & 0 & 0,80 & 5,3 & 0,10 & 13 & 0,0 \\
B+ CM & 0 & 0,55 & 7,0 & 0,14 & 13 & 0,02 \\
P & 0 & 0,55 & 6,7 & 0,14 & 13 & 0,01 \\
\hline
\end{tabular}

* CN- cobertura natural; P-Palma; B+CM- barramento associado à cobertura morta; SD- solo descoberto

\section{CONCLUSÕES}

1. A umidade do solo observada durante o período experimental apresentou elevada variação no tempo, estando relacionada aos diferentes tipos de cobertura e propriedades do solo.

2. A cobertura morta destacou-se como a prática conservacionista mais adequada para manutenção da umidade do solo nas condições do estudo. 
3. A umidade do solo apresentou dependência temporal superior a 5 dias, exibindo uma superposição de comportamento exponencial, com um periódico, e tendência de longa duração, esta presente apenas nos dois tratamentos conservacionistas considerados.

\section{AgRAdECIMENTOS}

Ao CNPq, FACEPE e FINEP, pelo apoio financeiro.

\section{LITERATURA CITADA}

Albuquerque, A. W.; Lombardi Neto, F.; Srinivasan, V. S.; Santos, J. R. Manejo da cobertura do solo e de práticas conservacionistas nas perdas de solo e água em Sumé, PB. Revista Brasileira de Engenharia Agrícola e Ambiental, v.6, p.136-141, 2002.

Ampofo, E.A. Soil moisture dynamics in Coastal Savanna soils in the tropics under different soil management practices. Hydrological Science, v.51, p.1194-1202, 2006.

Braida, J. A.; Cassol, E. A. Relações de erosão em entressulcos com o tipo e a quantidade de resíduo vegetal na superfície do solo. Revista Brasileira de Ciência do Solo, v.23, p.711$721,1999$.

Cantón, Y.; Solé-Benet, A.; Domingo, F. Temporal and spatial patterns of soil moisture in semiarid badlands of SE Spain. Journal of Hydrology, v.285, p. 199-214, 2004.

Cesare, L. de; Myers, D.E.; Posa, D. Fortran programs for spacetime modeling, Computers \& Geosciences, v.28, p.205-212, 2002.

Chen, L.; Huang, Z.; Gong, J.; FU, B.; Huang, Y. The effect of land cover/vegetation on soil water dynamic in the hilly area of the loess plateau, China. Catena, v.70, p.200-208, 2007.

Cogo, N. P. Uma contribuição à metodologia de estudo das perdas de erosão em condições de chuva natural. I. Sugestões gerais, medição dos volumes, amostragem e quantificação de solo e água da enxurrada. $1^{\text {a }}$ aproximação. In: Encontro Nacional de Pesquisa Sobre Conservação do Solo, 2, 1978, Passo Fundo. Anais...Passo Fundo: EMBRAPA, 1978. p.75-98.

Cogo, N. P.; Levien, R.; Schwarz, R. A. Perdas de solo e água por erosão hídrica influenciadas por métodos de preparo, classes de declive e níveis de fertilidade do solo. Revista Brasileira de Ciência do Solo, v.27, p.743-753, 2003.

EMBRAPA - Empresa Brasileira de Pesquisa Agropecuária. Centro Nacional de Pesquisa de Solos. Manual de métodos de análise de solo. 2.ed. Rio de Janeiro EMBRAPA, 1997. 212p. Documentos, 1.

Galindo, I. C. L.; Ribeiro, M. R.; Santos, M. F. A. V.; Lima, J. F. W. F.; Ferreira, R. F. A. L. Relações solo-vegetação em áreas sob processo de desertificação no município de Jataúba, PE. Revista Brasileira de Ciência do Solo, v.32, p.1283-1296, 2008.
Genuchten, M. T. van. A closed-form equation for predicting the hydraulic conductivity of unsaturated soils. Soil Science Society American Journal, v.44, p.892-898, 1980.

Greco, R.; Guida, A. Field measurements of topsoil moisture profiles by vertical TDR probes. Journal of Hydrology, v.348, p.442-451, 2008.

Journel, A. G.; Huijbregts, J. Mining geostatistics, Academic Press: London, 1978. 599p.

Medeiros, J. D. F; Goldenfum, J. A; Clarke, R. T. Variabilidade espacial do conteúdo de água no solo numa pequena bacia rural: Análise da estabilidade temporal do padrão espacial do conteúdo de água no solo. Revista Brasileira de Recursos Hídricos, v.12, p.53-63, 2007.

Montenegro, A. A. A.; Montenegro, S. M. G. L. Variabilidade espacial de classes de textura, salinidade e condutividade hidráulica de solos em planície aluvial. Revista Brasileira de Engenharia Agrícola, v.10, p.30-37, 2006.

Pan, Y. X; Wang, X. P; Jia, R. L.; Chen, Y. W.; He, M. Z. Spatial variability of surface soil moisture content in a re-vegetated desert area in Shapotou, Nothern China. Journal of Arid Enviroments, v.72, p.1975-1683, 2008.

Pereira, S.; Oliveira Filho, D.; Mantovani, E. C.; Ramos, M. M.; Martins, J. H. Reflectometria no domínio do tempo na determinação do conteúdo de água no solo. Revista Brasileira de Engenharia Agrícola e Ambiental, v.10, p.306314, 2006.

Porporato, A., D’Odorico, P., Laio, F., Ridolfi, L., RodriguezIturbe, I. Ecohydrology of water-controlled ecosystems. Advances in Water Resources, v.25, p.1335-1348, 2002.

Ramos, M. C.; Martínez-Casasnovas, J. A. Impact of land leveling on soil moisture and runoff variability in vineyards under different rainfall distributions in a Mediterranean climate and its influence on crop productivity. Journal of Hydrology, v.321, p.131-146, 2006.

Richard, M., Petrone, J. S., Price, S. K., Waddington, J. M. Statistical characterization of the spatial variability of soil moisture in a cutover peatland. Hydrological Processes, v.18, p.41-52, 2004.

Richards, L. A. Physical conditions of water in soil. In: Black, C. A., (ed.). Methods of soil analysis. Madison: American Society Agronomy, 1965. p.128-152.

Robertson, G. P. GS+: Geostatistics for the environmental sciences - GS+ User's Guide. Plainwell, Gamma Design Soffware, 1998. 152p.

Santos, T. E. M.; Montenegro, A. A. A.; Pedrosa, M. E. R. Características hidráulicas e perdas de solo e água sob cultivo do feijoeiro no semi-árido. Revista Brasileira de Engenharia Agrícola e Ambiental, v.13, p.217-225, 2009.

Santos, T. E. M.; Montenegro, A. A. A.; Silva Júnior, V. P.; Montenegro, S. M. G L. Erosão hídricaeperda de carbono orgânico em diferentes tipos de cobertura do sol o no semiárido, em condições de chuvasimulada. RevistaBrasileira deReqursos Hídricos, v. 13, p.29-39, 2008.

SAS. TheSASSystem for windows: Rel ease version: 6.8, 3.ed. Cary, 1998. CD-Rom.

Statsoft. Statistica: Data analysis software system; version 6. [S. L.], 2001. 